\title{
Fieldwork and social science research ethics
}

\author{
QUDSIYA CONTRACTOR
}

Researcher, D-302, Powai Park, Hiranandani Gardens, Powai, Mumbai 400076 INDIA email: qudsiya.contractor@gmail.com

\begin{abstract}
Fieldwork as a part of social science research brings the researcher closest to the subject of research. It is a dynamic process where there is an exchange between the researcher, participants, stakeholders, gatekeepers, the community and the larger sociopolitical context in which the research problem is located. Ethical dilemmas that surface during fieldwork often pose a unique challenge to the researcher. This paper is based on field experiences during an action research study conducted with a human rights perspective. It discusses the role conflict that researchers face during fieldwork in a situation of humanitarian crisis. It raises issues pertaining to the need to extend the ethical decision-making paradigm to address ethical dilemmas arising during the course of fieldwork.
\end{abstract}

This paper is based on fieldwork experiences (2003-4) during a study conducted by the Centre for Enquiry into Health and Allied Themes (CEHAT) to understand the consequences of involuntary resettlement on the lives of slum dwellers. The study was an action-research project; apart from documenting and studying the implications of resettlement on the community's health, education, work, social security and social life, it was also aimed at supporting the community's efforts to address its own concerns and needs post resettlement. The fieldwork raised certain key concerns. First, researchers were faced with a conflict of roles during data collection in situations of humanitarian crisis - the role of a researcher versus that of an intervener. Second, researchers faced unanticipated ethical dilemmas during the course of fieldwork. Sufficient preparation prior to fieldwork helps anticipate social, psychological and economic risks and, therefore, the possibility of resolving ethical dilemmas with the help of the ethics framework. However, unanticipated ethical dilemmas form a necessary part of fieldwork. Third, it raised certain concerns in the context of conducting social science research in situations of human rights violations.

\section{Role conflict: researcher or practitioner?}

Since the study was aimed at understanding the impact of involuntary resettlement on people's well being and social life, the tools included a self-rating questionnaire developed by the World Health Organization, with 20 questions on general wellbeing. When we started conducting the interviews, researchers were not prepared for the emotional and mental trauma that women faced as a result of the resettlement. The hardships associated with the resettlement were superimposed onto their already difficult daily life experiences, most of which were already painful. Researchers found that women often broke down towards the end of the interview. They were in a situation that required intervention such as providing emotional support to the women at the end of the interview. Several women also shared problems that were not directly linked to the objectives of the study, and asked for help such as information on social welfare schemes for the differently-abled, legal support for divorce from a violent husband, or employment.

Another situation during the course of data collection arose when the community faced an acute water crisis. The area's water connection had been stopped because the bills had not been paid. The amount due was much higher than what the residents could afford. Community leaders suggested that the dues included payment for the water used during the construction of the buildings - which had been wrongly charged to the residents. As a result, residents of the resettlement would have to collect water for washing and bathing from a rainwater-fed stream. Drinking water was bought from a nearby slum. The water prices in the locality eventually soared, leaving the poorest with no option but to use the stream water for drinking. At one point a group of men, women and children, carrying empty water pots, marched off to the nearest ward office to voice their protest against the withdrawal of the water supply.

Researchers faced a two-fold dilemma. First, it seemed pointless to continue with data collection in a situation where the community was grappling with a crisis. This situation required the researchers to intervene and address the problem. Data collection was withheld till the water problem was resolved. Team members tried to respond to the community's needs. The situation did not change; at any given time of day men, women and children would be walking to the stream with containers to collect water. Others would be sitting waiting for the supply to be restored. Stories of negotiations between the Brihanmumbai Municipal Corporation and community leaders did the rounds of the colony. The team felt increasingly distressed by the fact that they could not do anything to resolve the situation. The expectation of community members that the researchers would do something put the researchers under pressure. They were being forced to go beyond the role of a researcher. They were being forced to intervene in a situation taking place within the area that they were studying. 


\section{Ethical dilemmas in human rights research}

As mentioned earlier, the main objective of the study was to understand and document the impact of involuntary resettlement of the lives of the slum community. It therefore seemed logical to make a comparison with life before resettlement in order to assess the social impact of resettlement. Given the resettlement plan, the physical structure of the living space, the provision of infrastructure and the processes involved, it was evident that the condition and standard of living after the resettlement was not better than the earlier place of residence. If the researchers made a comparison between the two situations their findings could be misinterpreted to imply that the community wished to return to the slum that they had come from, and the associated living conditions. This would obscure the fact that large-scale development projects should be planned and implemented in a humane way, ensuring that there is no violation of human rights.

At the same time, an accurate picture of the impact of involuntary resettlement required a benchmark for the parameters included in the study. The impact of involuntary resettlement on a slum community would not seem significant enough unless it was compared with the earlier situation when the people were living in the slum.

During fieldwork the team became aware of that the new tenements were being sublet for residential and commercial purposes. They had not sought any direct information on this subject but they became privy to data on this subject. Such subletting is illegal according to the government's guidelines for resettlement. Revealing data on this subject would put the community at risk. The state might put pressure on the institution and the research team to part with such information. This would harm the individual members of the resettlement colony as well as the community as a whole. It would be very difficult to ensure anonymity and confidentiality for the community as a whole that participated in the study. At the same time, not revealing the data would mean keeping from the state information on violations of the law.

\section{Discussion}

One of the key issues in fieldwork is the extent of involvement and detachment between the researchers and the researched. Very often during fieldwork, a researcher may come across situations that require immediate action or intervention. In such a scenario, the researcher has often no choice but to respond to the crisis, going beyond the role of a researcher. The possibility of coming across such situations is often increased in the context of human rights research and action research. There may be a need locate the ethical responsibility of a social science researcher within the larger context of social responsibility and justice.

However, addressing a humanitarian crisis during fieldwork is often in conflict with the demands that the research process makes of the researcher. There is a need to address this conflict in order to enable more research to be conducted on human rights violations and situations of disasters. Addressing this conflict is also necessary to enable researchers to cope with the burden of moral and social responsibility while conducting research in such situations.

\section{Acknowledgements}

I would like to acknowledge the contribution of my team members, Shakuntala Bhalerao and Zainab Kadri, with whom I shared several thoughts and experiences of fieldwork during the study. Neha Madhiwala, who was also my team member and guide, contributed to the discussions mentioned in the paper. The views presented in this paper, however, remain my own. 